\title{
STRUCTURAL PERFORMANCE AND DESIGN METHOD OF NEW MORTISE-TENON FULL STEEL-TUBE SCAFFOLD
}

\author{
Liu Hongbo ${ }^{1,2}$, Zhou Yuan², Chen Zhiua ${ }^{1,2 *}$ and Liu Qun ${ }^{3}$ \\ ${ }^{1}$ State Key Laboratory of Hydraulic Engineering Simulation and Safety, Tianjin University, Tianjin 300072, China \\ ${ }^{2}$ School of Civil Engineering, Tianjin University, Tianjin 300072, China \\ ${ }^{3}$ China Academy of Building Research, Beijing 100013, China \\ *(Corresponding author: E-mail: zhchen@tju.edu.cn)
}

Received: 12 August 2016; Revised: 26 March 2017; Accepted: 25 June 2017

\begin{abstract}
A mortise-tenon steel-tube scaffold, a new steel-tube scaffold, was presented based on ancient mortise-tenon joint in wood structure. Because of better joint mechanics and higher bearing capacity than coupler-type steel-tube scaffold, this new scaffold possesses good market potential. Based on an analysis of the bearing mechanism, a finite element numerical analysis model for the mortise-tenon steel-tube scaffold was established in this study, which was validated as reasonable and accurate by experiment data. Influencing laws of storey height, vertical member interval, X-bracing layout, overall structure height, height of bottom horizontal tube, and height of upper cantilever bar on the mortise-tenon steel-tube scaffold were determined through parameter analysis. A simplified calculation formula of ultimate bearing capacity was established, which verified by FEM results and test data. Research results provide important references for future in-depth studies and engineering applications of the mortise-tenon steel-tube scaffold.
\end{abstract}

Keywords: Mortise-tenon joint, steel-tube scaffold, numerical simulation, parameter analysis, simplified calculation formula

DOI: 10.18057/IJASC.2018.4.2.9

\section{INTRODUCTION}

Scaffolds have been widely used in engineering construction as temporary supporting structures. Existing common scaffolds mainly include door-type steel-tube scaffold (Figure 1a), inserting-type steel-tube scaffold (Figure 1b), cuplock steel tubular scaffold (Figure 1c) and coupler-type steel-tube scaffold (Figure 1d). Because the scaffolds are usually used as a temporary supporting structure, its structural behavior and design method have not attracted adequate attention. In recent years, scaffold collapse accidents have occurred frequently because of poor site management and unreasonable design, thereby causing huge economic losses and casualties. Therefore, research on structural behavior and design method of scaffolds has attracted increasing attention in recent years.

Although the scaffold is a temporary structure, its mechanical properties are more complicated than those of a permanent steel structure because of complicated structural defects and damage distribution caused by repeated use. Chan et al. [1], Peng et al. [2-6], Yu et al. [7], and Weesner and Jones [8] conducted numerous experimental and theoretical studies on the stability capacity and design method of door-type scaffolds. Micha and Blazik-Borowa [9] determined the capacity of the key joint in inserting-type scaffolds using numerical analysis. Peng et al. [10] investigated the load capacities and failure modes of inserting-type scaffolds by experimental tests. Zhang et al. [11-13] conducted research on cuplock-type scaffolds using the probability-based design method. Beale et al. [14-16], Ao et al. [17], Yue et al. [18] and Liu et al. [19-20] conducted systematic studies on stability capacity and design method of multi-span coupler-type steel-tube scaffold using experimental research and numerical analysis. 


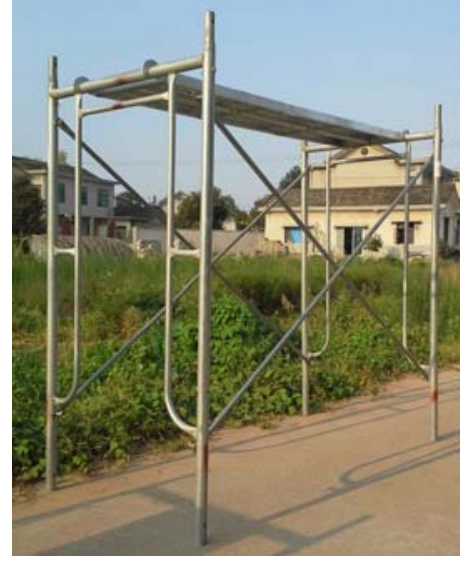

(a)Door-type Scaffolds

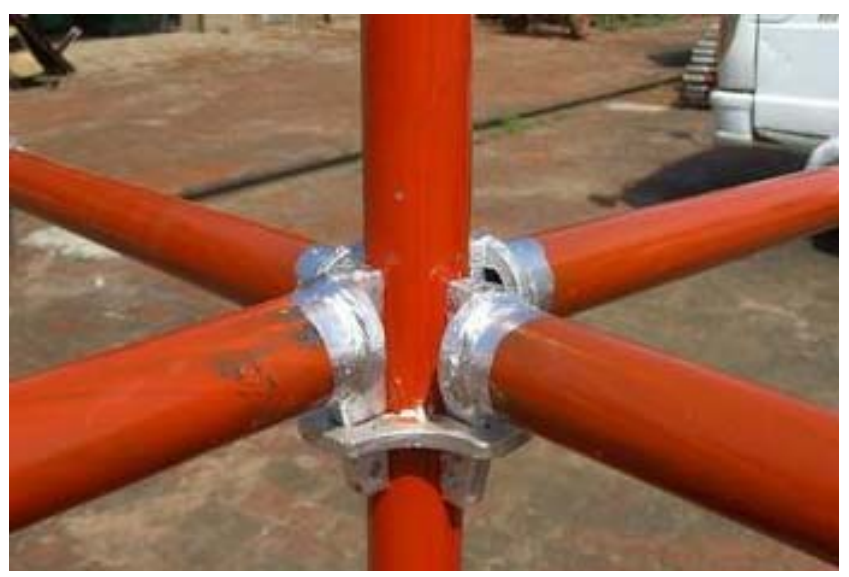

(b)Inserting-type scaffold

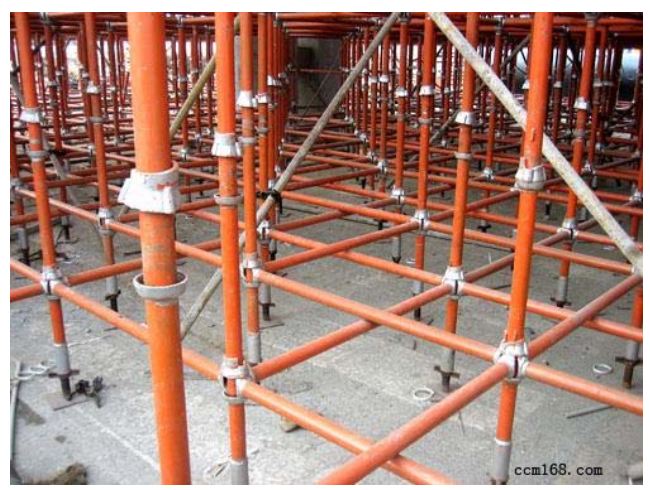

(c)Cuplok-type Scaffold

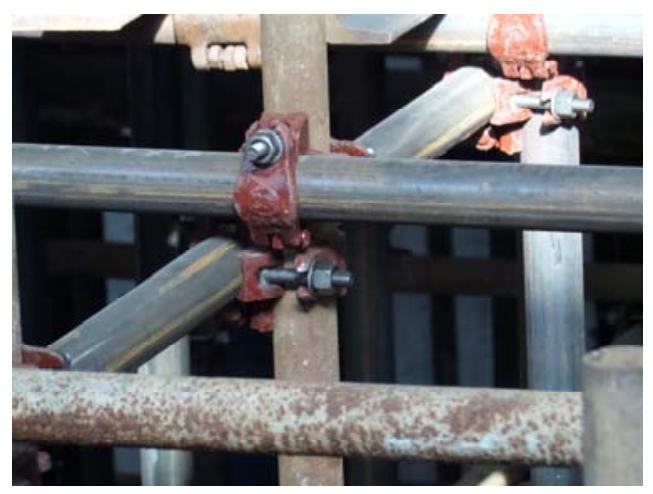

(d)Steel Tube-Coupler Scaffold

Figure 1. Four Types of Scaffolds

Engineering accident analysis shows that unstable connection performance of joints is the main cause of scaffold collapse [21]. To search for a safe and stable scaffold system, Tianjin University and Tianjin Xunan Jiahui Building Materials Technological Co. Ltd. developed the mortise-tenon steel-tube scaffold based on mortise-tenon joint in ancient wood structure. In this study, a numerical analysis model was proposed to analyze the structural behavior of effects of the mortise-tenon steel-tube scaffold, which was verified by experimental data. And a simplified calculation formula is also proposed to predict the ultimate bearing capacity of the mortise-tenon steel-tube scaffold.

\section{STRUCTURAL DETAIL OF MORTISE-TENON STEEL-TUBE SCAFFOLD}

The mortise-tenon steel-tube scaffold is composed of horizontal members, vertical members, adjustable support brackets, and ground members as shown in Figure 2. The adjustable support brackets are placed on top of the vertical members for transmitting construction loads. The ground members are set at the bottom of the vertical members to increase stability of the structure. 

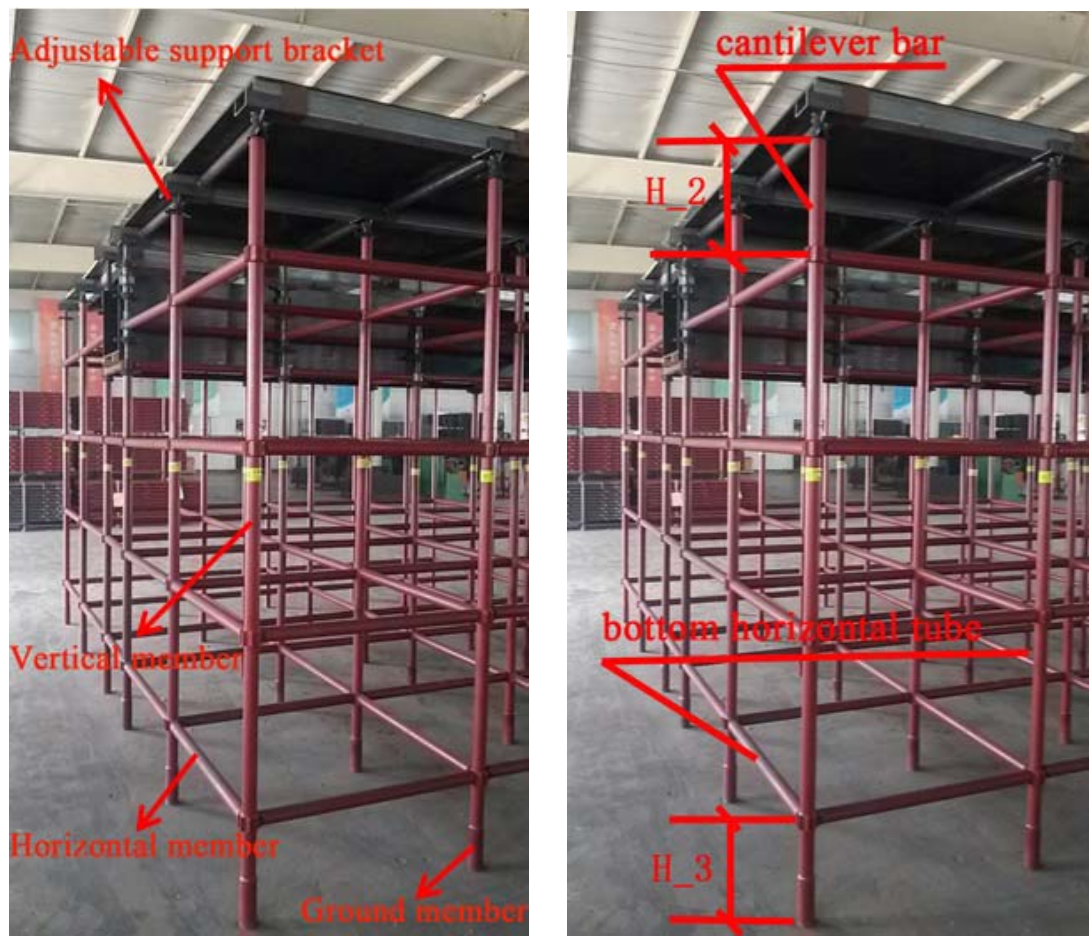

Figure 2. Structure of Mortise-tenon Steel-tube Scaffold

Compared with existing common scaffolds, the mortise-tenon joint is the main innovative point for the mortise-tenon steel-tube scaffold. The design of the mortise-tenon joint is inspired by the mortise-tenon joint in ancient wood structure. In fact, the mortise-tenon joint is a wedged concave-convex connection mode. The wedged convex is the tenon and the wedged concave is the mortise as shown in Figure 3 and Figure 4. The horizontal members are P48.3 mm $\times 3.5 \mathrm{~mm}$ standard steel tube with the tenon at two ends (Figure 3). The vertical members are P48.3 mm $\times 3.5$ $\mathrm{mm}$ standard steel tube with the mortise rings (Figure 4). The tenon on the horizontal member is inserted into the mortise ring of the vertical member, which achieves the connection of horizontal and vertical members (Figure 5). Since the mortise-tenon joint has good shear capacity and rotational rigidity, the bearing capacity of the mortise-tenon steel-tube scaffold was higher than that of other scaffolds.

The sleeve coupler is used to connect the vertical steel tubes as shown in Figure 6. The swivel coupler is used to connect the vertical steel tubes and X-bracing steel tubes as shown in Figure 7.

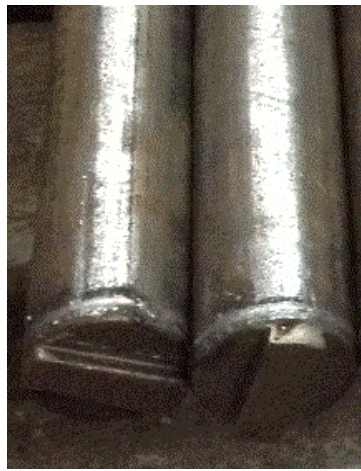

(a) Physical object Figure 3. Horizontal Member

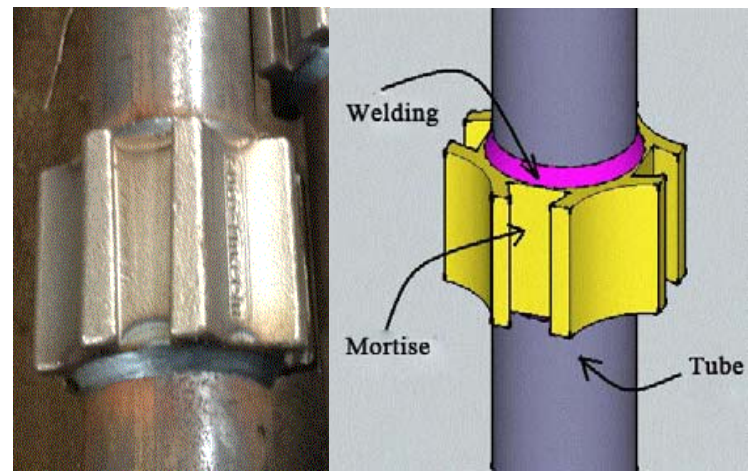

(b) Model

Figure 4. Vertical Member 


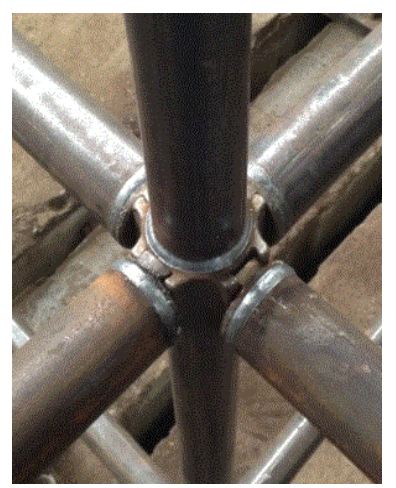

(a) Physical object

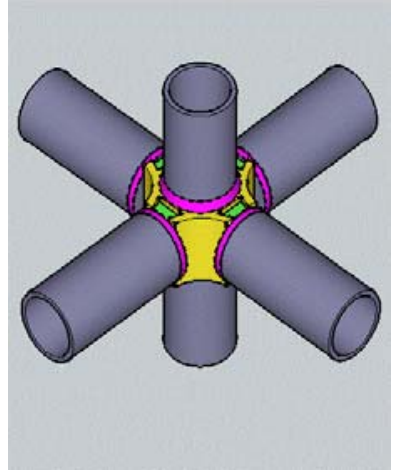

(b) Model

Figure 5. Mortise-tenon Joint

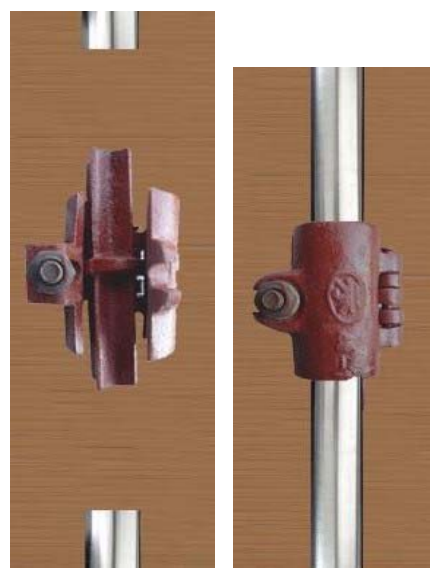

Figure 6. Sleeve Coupler

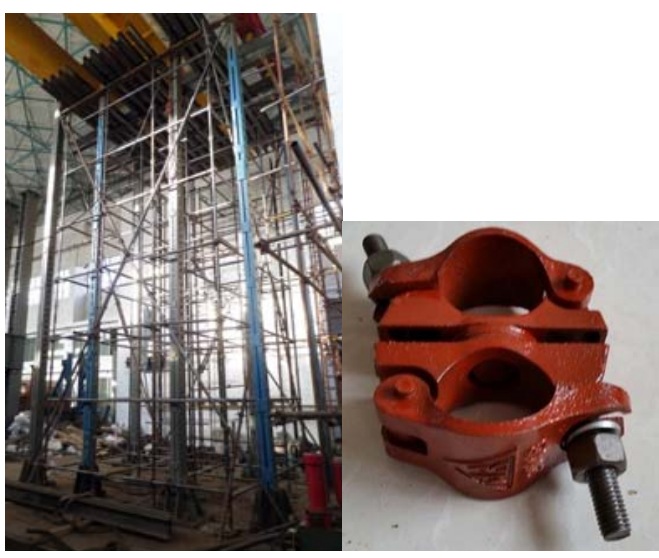

Figure 7. Swivel Coupler

\section{NUMERICAL ANALYSIS MODEL}

\subsection{Finite element Model}

The mortise-tenon joint is a typical semi-rigid node. Thus, the mortise-tenon steel-tube scaffold is a semi-rigid framework structure. In this study, a semi-rigid finite element model for the mortise-tenon steel-tube scaffold was established by ANSYS to accurately analyze its structural behavior.

In the mortise-tenon steel-tube scaffold, the vertical members are continuous at the mortise-tenon joint. The horizontal members are broken at the joint and form the framework structure with the vertical members through the mortise-tenon joint. In this paper, the horizontal and vertical members were simulated by BEAM188 element and the connection of the horizontal and vertical members was simulated by COMBIN14 element, thereby achieving the semi-rigid simulation of the mortise-tenon joint. The datailed modeling steps are as following:

Step 1: The horizontal and vertical member models are established by BEAM188 element according to spatial geometrical position of the structure. The vertical members have the same node at the mortise-tenon joint and the horizontal members have different nodes at the joint (Figure 8). To consider local instability of members, a member between every two joints is divided into 10 segments. In other words, each member are simulated by 10 BEAM188 elements. This model involves the local instability simulation of members and increases numerical analysis accuracy. 
Step 2: Translational degrees of three nodes at the vertical-horizontal member joint (UX, UY, and $\mathrm{UZ}$ ) are coupled by the finite element node coupling technology.

Step 3: COMBIN14 element is established by the horizontal member nodes and the vertical member nodes at the corresponding position. This element is used to simulate semi-rigid features of the mortise-tenon joint. Rigidity value of the COMBIN14 element was determined by tests as shown in Section 3.2.

Step 4: Natural pressure contact occurs between the vertical member and the ground. No relative slippage between members and the ground is found in engineering applications and prototype test. Therefore, a hinge joint can be set at the bottom of the vertical members of the mortise-tenon steel-tube scaffold. In other words, translational degrees of freedom of the bottom nodes of vertical members are constrained. Concentrated force is applied at the top nodes of the vertical element of scaffold structures.

Step 5: The first buckling mode identified from the eigenvalue buckling analysis was generally considered as the most critical one, and applied as initial geometric imperfection in the nonlinear analysis. According to literature, the maximum imperfection allowed in practice is $0.05 \mathrm{~m}$ for scaffolds with height less than $10 \mathrm{~m}$. Therefore, an initial geometric imperfection was applied to the model with amplitude of $0.05 \mathrm{~m}$ and a shape of the first buckling mode.

Step 6: Using Newton-Raphson solving method, the second-order analysis considering the geometric nonlinear effect and material nonlinear effect are accomplished to determine the nonlinear buckling strength and failure mode of the scaffold.

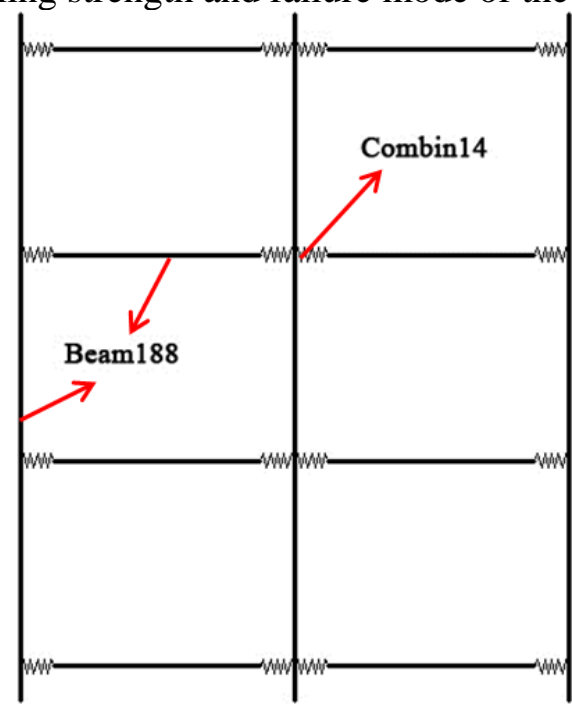

(a) Three-dimensional sketch

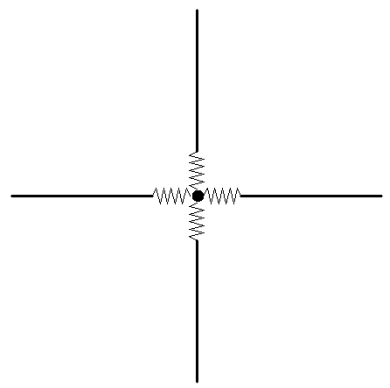

(b) Plan sketch

Figure 8. FE Model of Connection between Vertical and Horizontal Members

\subsection{Values of Key Parameters in FE Model}

In the finite element model, the stress-strain relation of steel tubes was simulated by the ideal elastic-plastic model. When analyzing the structural performance of the prototype tested specimens, the basic mechanical properties of the steel tubes (Material model 1 in Table 1) were collected through static tension test. For structural parameter analysis of the mortise-tenon steel-tube scaffold, the basic mechanical properties of the steel tubes (Material model 2 in Table 1) were determined according to national code. 
Table 1. Basic Mechanical Properties of Steel Tubes

\begin{tabular}{cccc}
\hline Parameters & Elasticity modulus (Mpa) & Yield strength (Mpa) & Poisson's ratio \\
\hline Material model 1 & $2.25 \times 10^{5}$ & 360 & 0.3 \\
Material model 2 & $2.06 \times 10^{5}$ & 205 & 0.3 \\
\hline
\end{tabular}

Rotational stiffness and shear strength of the mortise-tenon joint was determined by tests [21]. The rotational stiffness of three mortise-tenon joint specimens was tested by the loading program in Figure 9. Three Moment-Rotation curves were obtained, as shown in Figure 10. According to the curves in Figure 10, the initial rotational stiffness of three mortise-tenon joints specimens were calculated through linear fitting, and their values were 13.38, 16.07, and $19.80 \mathrm{kN} \cdot \mathrm{m} / \mathrm{rad}$ respectively. For vertical members of the mortise-tenon steel-tube scaffold, the horizontal members on two sides are connected by two mortise-tenon joints (Figure 5). For the coupler-type steel-tube scaffold, the horizontal members on two sides of the vertical members are connected by a right-angle coupler (Figure 11). Therefore, the rotational constraint stiffness of vertical members in the mortise-tenon steel-tube scaffold has much higher than that in the coupler-type steel-tube scaffold.

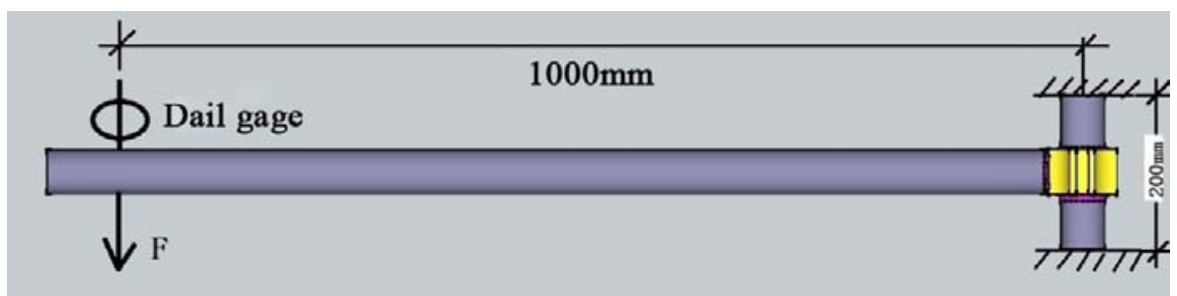

Figure 9. Loading Program of Rotational Stiffness Test of Mortise-tenon Joint

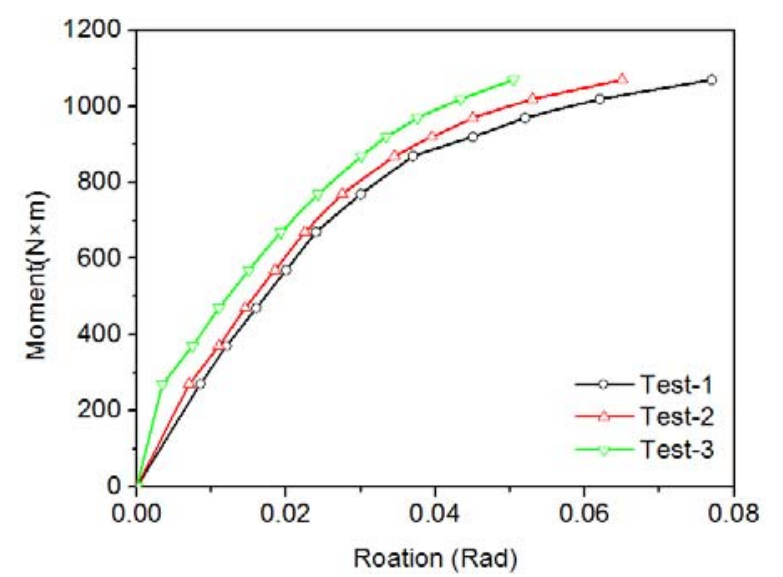

Figure 10. Moment-rotation Curves of Mortise-tenon Nodes 


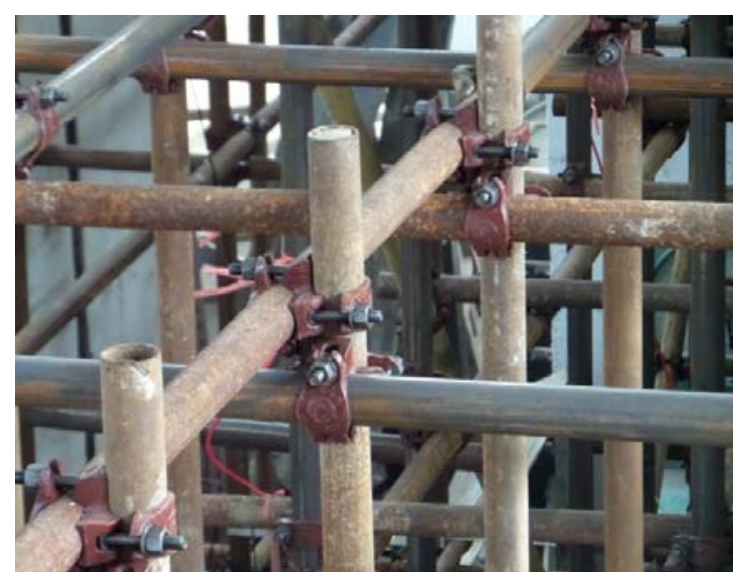

Figure 11. Connection of Horizontal and Vertical Members in Coupler-type Scaffold Structure

Shear strength of the mortise-tenon joint was determined by the loading program shown in Figure 12 [21]. The shear strength of three mortise-tenon joint specimens was tested, and their shear strengths were 94.7, 92.2, and $93.5 \mathrm{kN}$ respectively, which were much higher than the vertical shear strength of the right-angle coupler.

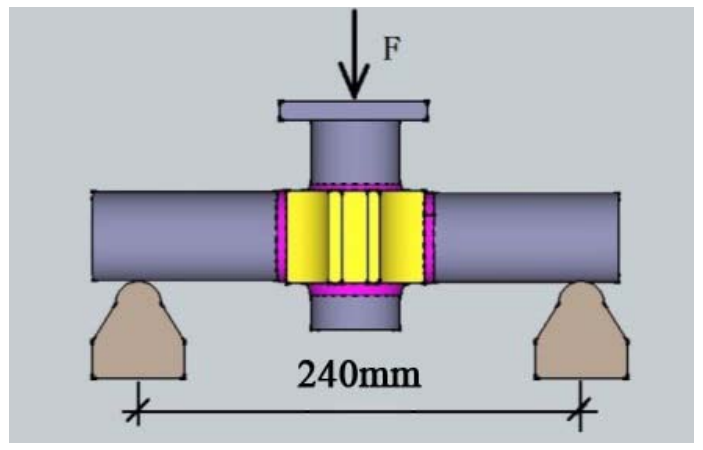

Figure 12. Shear Strength Test of Mortise-tenon Joint

\subsection{Experimental Verification}

A total of 11 mortise-tenon scaffold prototype tests were carried out from 2013 to 2014 at the Structural Engineering Laboratory of Tianjin University, and these test data were used to verify the accuracy of the numerical analysis model. Structural layout and basic geometric parameters of the 11 test models are shown in Figures. 13 14 and Table 2. Four $10 \mathrm{~m}$ high loading frames were fabricated for the tests. Two 50-ton hydraulic jacks were fastened to the top of each loading frame, and applied vertical loads to the two top steel distribution beams. The loads were then transferred to a group of bottom steel distribution beams in the perpendicular direction, and finally to the scaffold system, as shown in Figure 15. In this way, vertical uniform loads were applied to the top of the scaffold system through two steel tubes right below the bottom distribution beams and the U-heads. Based on the finite element analysis model presented in Sections 3.1 and 3.2, the ultimate bearing capacities and failure modes of these 11 test models were analyzed and compared with those from the test results. The results are presented in Table 3 and Figures. 15 17. As shown in Table 3, the maximum error between the numerical analysis and test results of the ultimate bearing capacity is $30.87 \%$ and the average error are $11.02 \%$. The buckling form of the mortise-tenon scaffold with $\mathrm{X}$-bracing is mainly the local lateral buckling of the vertical members at the upper two-storey vertical members as shown in Figure 15. The buckling form of the mortise-tenon scaffold without 
$\mathrm{X}$-bracing is mainly the overall lateral buckling of the structure as shown in Figure 16. Though comparison the bearing capacities, failure modes and load-displacement curves as shown in Figures. $15 \sim 17$, it is clear that numerical analysis results are in accordance with test results. In other words, the proposed numerical analysis model can reasonably predict the ultimate bearing capacity and failure mode of the mortise-tenon steel-tube scaffold.

The prototype test model of the mortise-tenon steel-tube scaffold (ST5) has consistent structural parameters of the prototype test model of the coupler-type mortise-tenon steel-tube scaffold (ST6) [19]. Their ultimate bearing capacities are $69.4 \mathrm{kN}$ and $20.68 \mathrm{kN}$, respectively. Under the same structural parameters, the ultimate bearing capacity of the mortise-tenon steel-tube scaffold is approximately $235.59 \%$ higher than that of the coupler-type steel-tube scaffold.

Table 2. Prototype Test Model of Mortise-tenon Scaffold

\begin{tabular}{ccccccc}
\hline No. & S_1 $(\mathrm{m})$ & S_2 $(\mathrm{m})$ & H_1 $(\mathrm{m})$ & $\mathrm{n}$ & $\mathrm{m}$ & X-bracing \\
\hline ST1 & 0.9 & 0.9 & 0.6 & 5 & 12 & $\mathrm{~N}$ \\
ST2 & 0.9 & 0.9 & 0.6 & 5 & 12 & $\mathrm{Y}$ \\
ST3 & 0.6 & 0.6 & 1.2 & 6 & 6 & $\mathrm{~N}$ \\
ST4 & 0.6 & 0.6 & 1.2 & 6 & 6 & $\mathrm{Y}$ \\
ST5 & 0.6 & 0.6 & 0.6 & 6 & 12 & $\mathrm{~N}$ \\
ST6 & 0.9 & 0.9 & 1.2 & 4 & 6 & $\mathrm{~N}$ \\
ST7 & 0.9 & 0.9 & 1.2 & 4 & 6 & $\mathrm{Y}$ \\
ST8 & 0.9 & 0.9 & 1.8 & 4 & 4 & $\mathrm{~N}$ \\
ST9 & 0.9 & 0.9 & 1.8 & 4 & 4 & $\mathrm{Y}$ \\
ST10 & 1.2 & 1.2 & 1.2 & 3 & 6 & $\mathrm{~N}$ \\
ST11 & 1.2 & 1.2 & 1.2 & 3 & 6 & $\mathrm{Y}$ \\
\hline
\end{tabular}

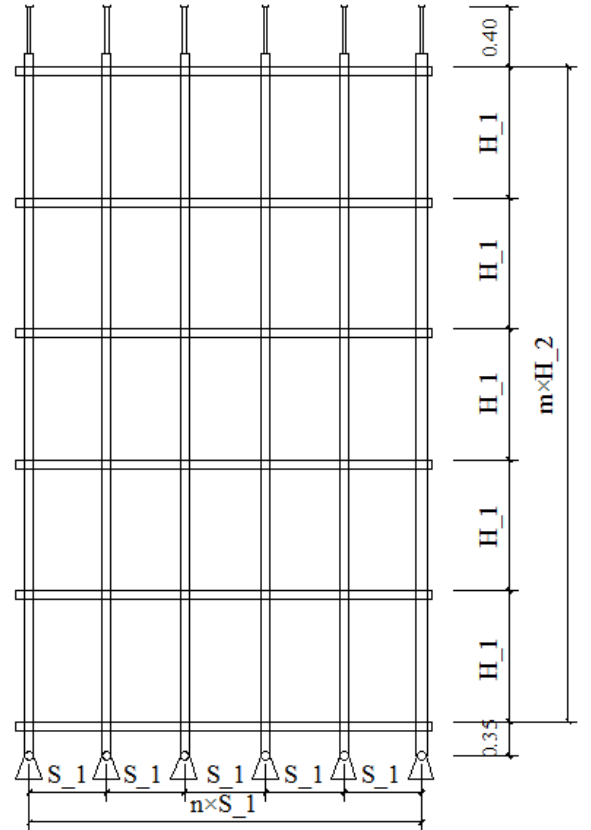

(a) Vertical view

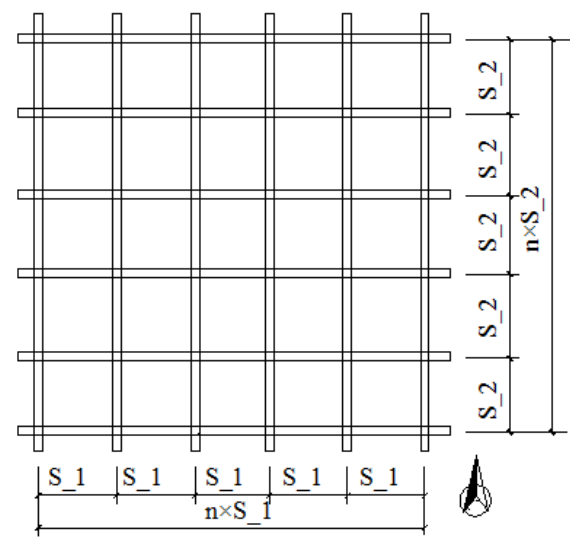

(b) Plan view

Figure 13. Schematic View of Prototype Test Model of Mortise-tenon Scaffold without X-bracing 


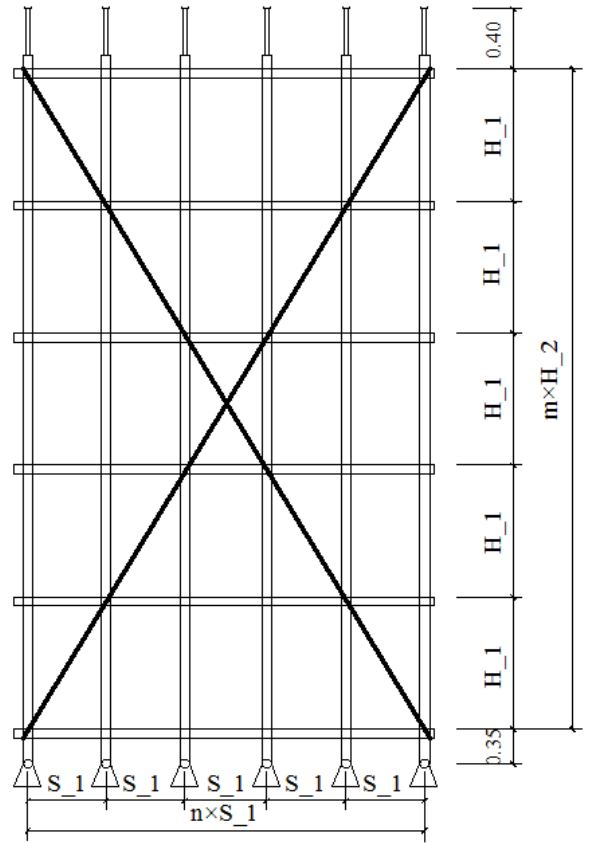

(a) Vertical view

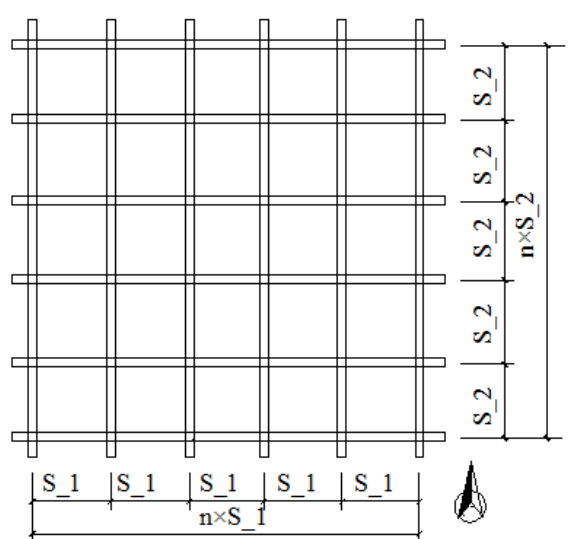

(b) Plan view

Figure 14. Schematic View of Prototype Test Model of Mortise-tenon Scaffold with X-bracing

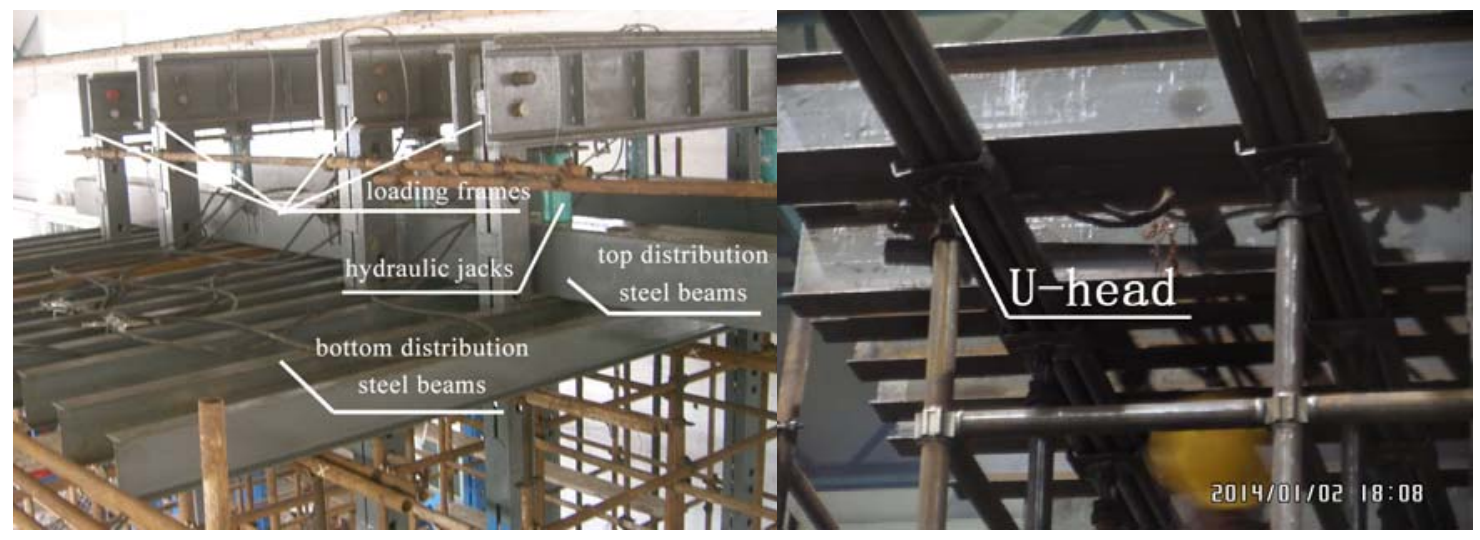

Figure 15. Loading Mechanism and Test Set-up

Table 3. Comparison between Test Results and FE Result of Ultimate Bearing Capacity

\begin{tabular}{cccc|cccc}
\hline No. & Test result $(\mathrm{kN})$ & FE result $(\mathrm{kN})$ & Error & No. & Test result(kN) & FE result $(\mathrm{kN})$ & Error \\
\hline ST1 & 45.8 & 59.9 & 30.87 & ST7 & 56.0 & 58.0 & 3.51 \\
ST2 & 73.8 & 71.0 & -3.86 & ST8 & 24.0 & 24.3 & 1.17 \\
ST3 & 44.5 & 36.5 & -17.94 & ST9 & 46.4 & 46.2 & -0.36 \\
ST4 & 68.1 & 64.3 & -5.62 & ST10 & 37.5 & 32.7 & -12.70 \\
ST5 & 69.4 & 61.3 & -11.64 & ST11 & 46.9 & 57.5 & 22.59 \\
ST6 & 38.0 & 33.8 & -11.00 & & & & \\
\hline
\end{tabular}




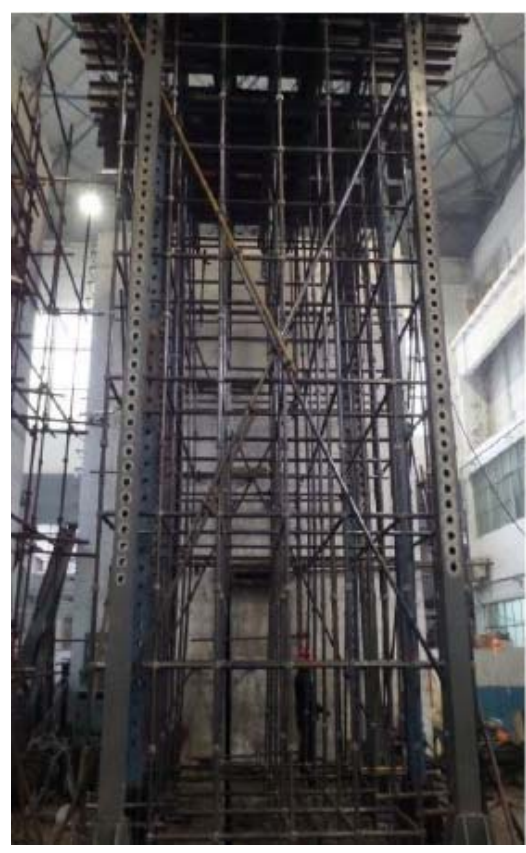

(a) Test

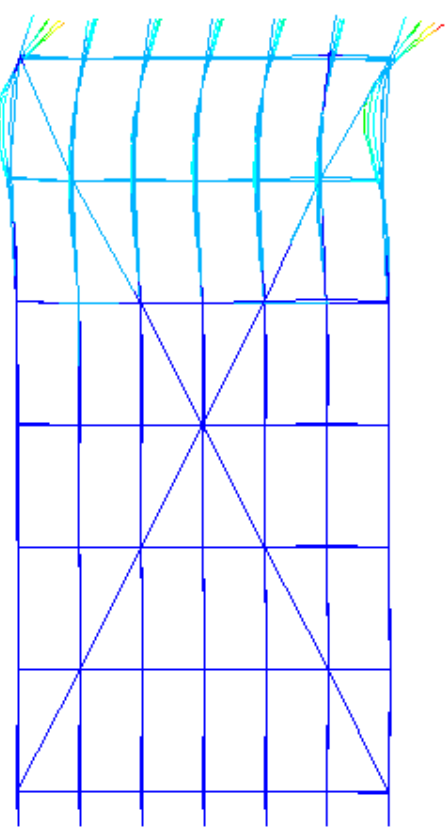

(b) Finite element

Figure 15. Failure Mode Comparison of Test Model 4

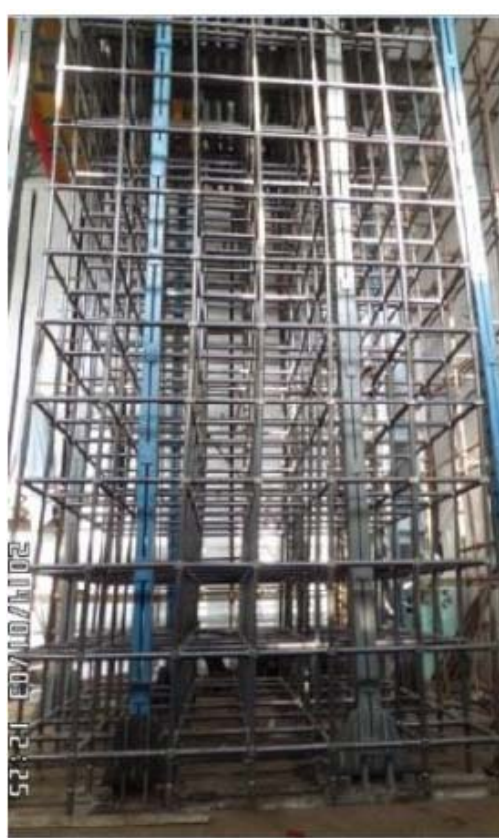

(a) Test

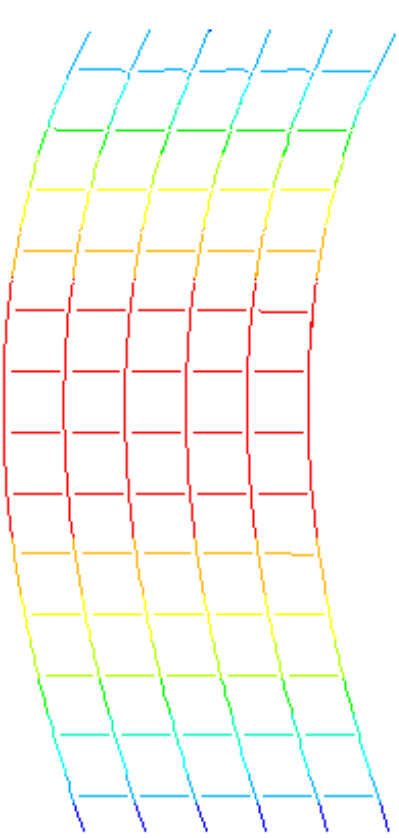

(b) Finite element

Figure 16. Failure Mode Comparison of Test Model 5 


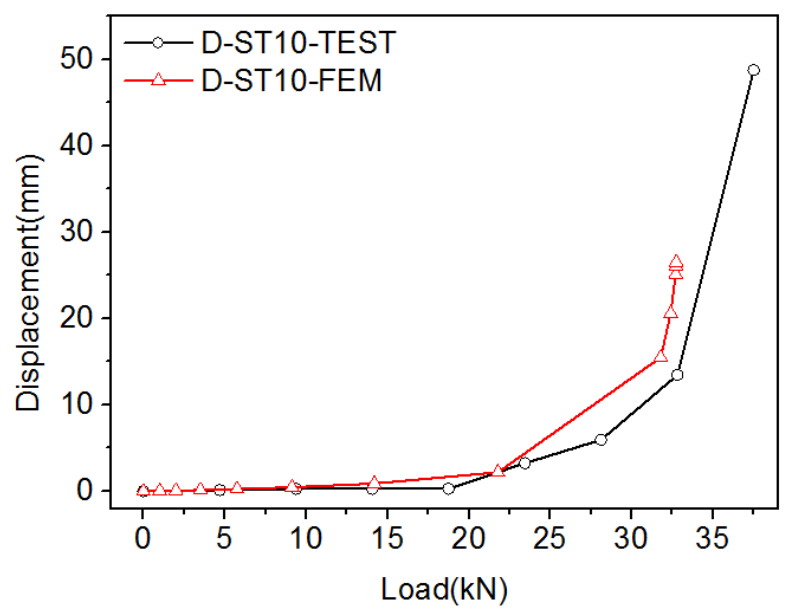

Figure 17. Load-Displacement Curves Comparison of Test Model 10

\section{ANALYSIS OF STRUCTURAL PERFORMANCE}

In this section, the effect of structural parameters on structural behavior of the mortise-tenon steel-tube scaffold is discussed using the numerical analysis method. In the numerical simulation of the mortise-tenon steel-tube scaffold test model in Section 3, the basic mechanical parameters of the steel-tube materials were determined through static tension tests so that the numerical simulation would approximate the actual performance of the test model. However, the purpose of numerical analysis of the mortise-tenon steel-tube scaffold in this section was to provide references for engineering applications. Therefore, the mechanical properties of the steel-tube materials in this section were determined according to the national code (Material model 2 in Table 1).

In the engineering application of the mortise-tenon steel-tube scaffold, the steel tube and mortise-tenon joint are constants for the easy materials reuse. The steel tube generally uses P48 $\mathrm{mm} \times 3.5 \mathrm{~mm}$ and the mortise-tenon joint matches that of the steel tube. Therefore, the main influencing factors of the structural performance of the mortise-tenon steel-tube scaffold are the geometric parameters, including storey height, vertical member interval, height of bottom horizontal tube (H_3 shown in Figure, 2), height of cantilever bar (H_2 shown in Figure, 2), overall structure height and X-bracing layout. In this study, the effects of these factors were studied through a series parameter analysis.

To analyze the effects of storey height and vertical member interval on the structural performance, the overall structure height, height of the bottom horizontal tube, and height of the cantilever bar were fixed at approximately $8 \mathrm{~m}, 0.35 \mathrm{~m}$, and $0.4 \mathrm{~m}$ respectively, and No X-bracing was used. A total of 25 structural models with different storey height and vertical member intervals were established. Their ultimate bearing capacities were obtained as shown in Figures. 18 and 19. It is clear that the vertical member interval had a minor effect on the ultimate bearing capacity, but the storey height influenced significantly. The ultimate bearing capacity decreased by approximately $13 \%-23 \%$ when the storey height increased by $0.3 \mathrm{~m}$. The smaller the structure height is, the greater is the bearing capacity reduction. 


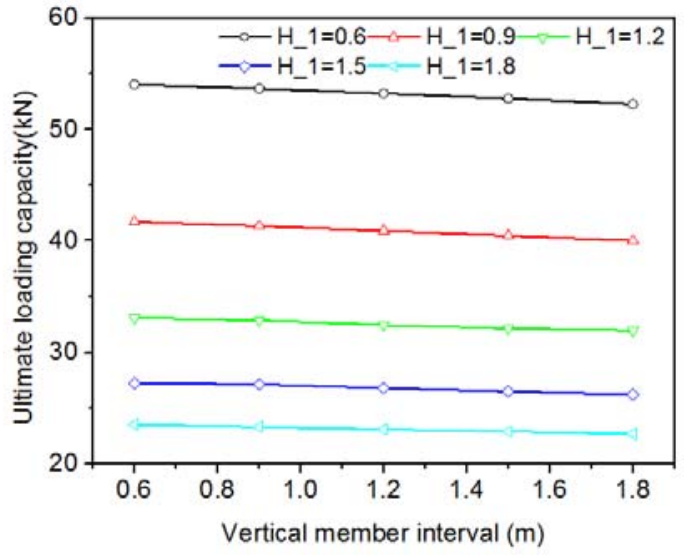

Figure 18. Parameter Analysis of Vertical Interval

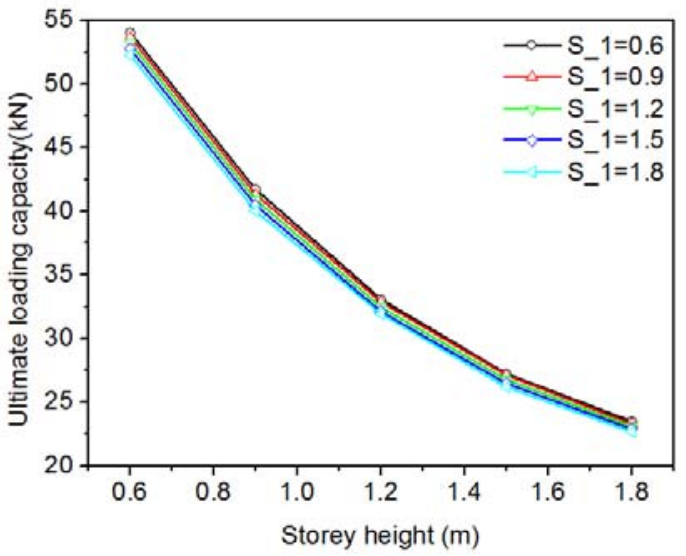

Figure 19. Parameter Analysis of Member Storey Height

To analyze the effects of the height of the bottom horizontal tube and the height of the cantilever bar on the structural performance of the mortise-tenon steel-tube scaffold, the overall structure height, storey height, and vertical member interval were fixed at approximately $8 \mathrm{~m}, 0.9 \mathrm{~m}-1.8 \mathrm{~m}$, and $0.9 \mathrm{~m}$ respectively. No X-bracing was used. A series of analysis models were established with different height of the bottom horizontal tube and height of the cantilever bar. In the parameter analysis of height of the bottom horizontal tube, the height of the cantilever bar was fixed at $0.4 \mathrm{~m}$. In the parameter analysis of the cantilever bar height, the height of the bottom horizontal tube was fixed at $0.35 \mathrm{~m}$. Results are presented in Figures. 20 and 21. It is clear that when the storey height was higher than $0.9 \mathrm{~m}$, the height of the bottom horizontal tube and the cantilever bar basically had little effect on the ultimate bearing capacity. When the storey height was less than $0.9 \mathrm{~m}$, the height of the bottom horizontal tube was less than $0.3 \mathrm{~m}$, and the height of the cantilever bar was less than $0.4 \mathrm{~m}$. The ultimate bearing capacity of the structure remained basically the same despite the height variation of the bottom horizontal tube and the cantilever bar. When the storey height is more than $0.9 \mathrm{~m}$, the height of the bottom horizontal tube increases to $0.4 \mathrm{~m}$ and $0.5 \mathrm{~m}$, and the ultimate bearing capacity decreases by $9 \%$ and $19 \%$ up to the maximum; when the cantilever height increases to $0.5 \mathrm{~m}$, the ultimate bearing capacity decreases by $7 \%$ up to the maximum.

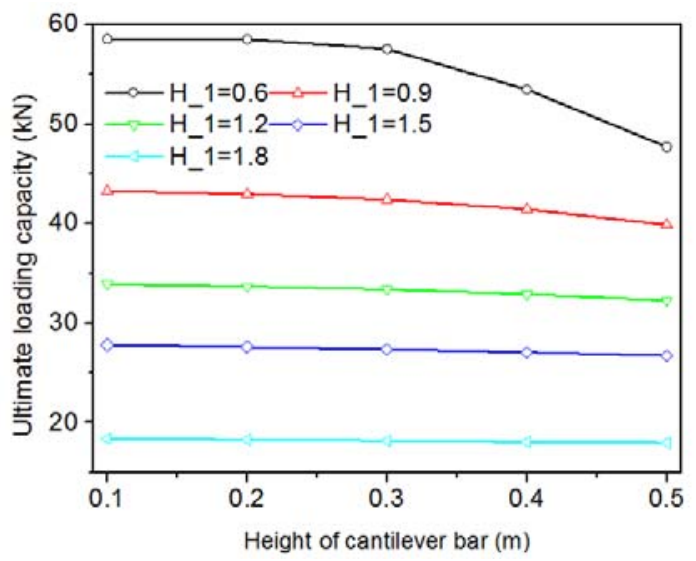

Figure 20. Parameter Analysis of Height of Cantilever Bar

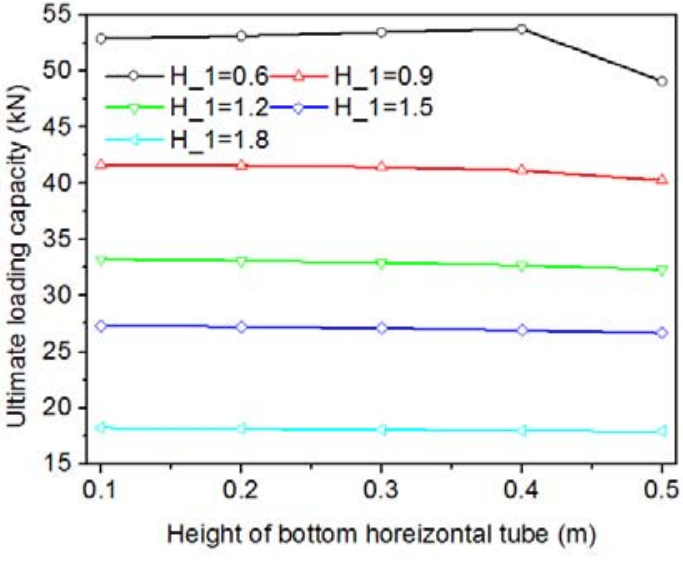

Figure 21. Parameter Analysis of Height of Bottom Horizontal Tube 
In order to analyze the effect of X-bracing on the ultimate loading capacity, the X-bracings were set in all models established for the storey height and vertical-member interval parameter analysis. The analysis results were shown in Figure 22, and it is clear that the X-bracing layout have strengthened the ultimate bearing capacity significantly. The strengthen effect is closely related to the storey height but less correlated to the vertical member interval. The average strengthen coefficients of the ultimate bearing capacity were $1.0,1.24,1.45,1.49$, and 1.30 when the storey heights were $0.6,0.9$, $1.2,1.5$, and $1.8 \mathrm{~m}$.

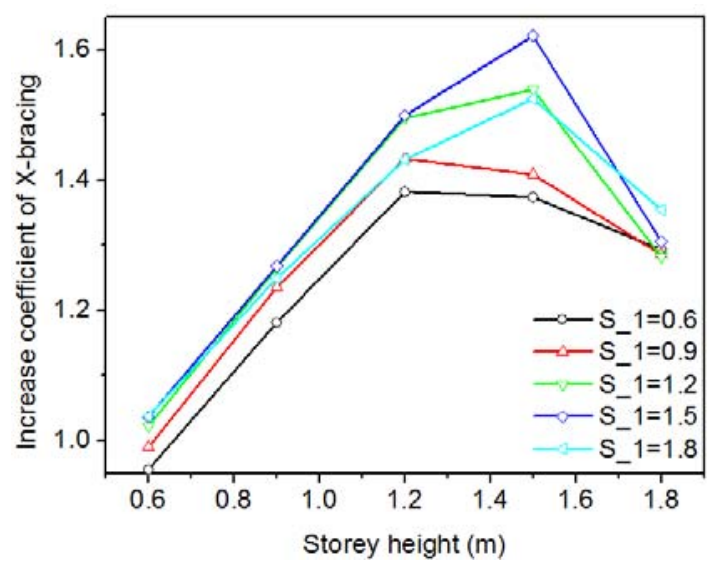

(a) Variation of storey height

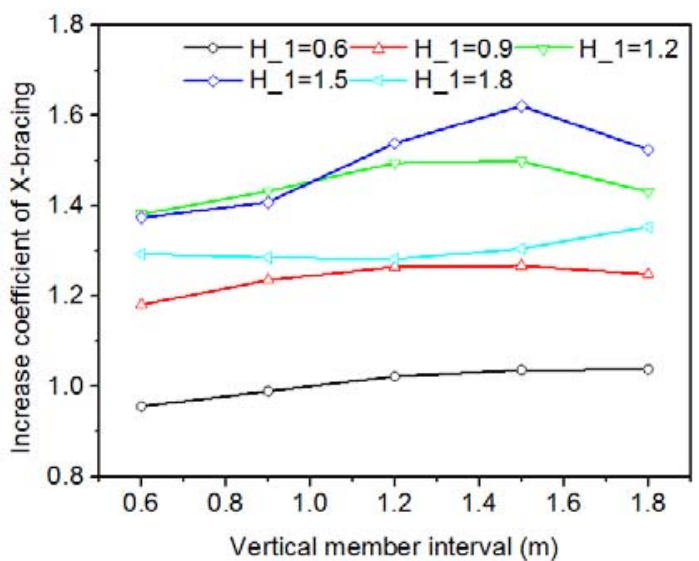

(b) Variation of vertical member interval

Figure 22. Effect of X-bracing Layout on Ultimate Bearing Capacity

The effect of the overall structure height on the ultimate bearing capacity was also studied through a series of models without X-bracing. In these models, the overall structure height was different, but the vertical member interval $(0.9 \mathrm{~m})$, storey height $(0.9,1.2$, or $1.5 \mathrm{~m})$, height of bottom horizontal tube $(0.35 \mathrm{~m})$, and height of cantilever bar $(0.4 \mathrm{~m})$ were fixed. The analysis results are shown in Figure 23. The overall structure height affected the ultimate bearing capacity significantly. Such an effect decreased with the increase of the overall structure height. Furthermore, the negative correlation between the overall structure height and the ultimate bearing capacity was further intensified as the storey height increased. When the overall structure heights were 8, 12, 16, and 20 $\mathrm{m}$, the ultimate bearing capacity decreased by approximately $19 \%, 27 \%$, 30\%, and $29 \%$ compared with the capacity when the overall structure height was $4 \mathrm{~m}$.

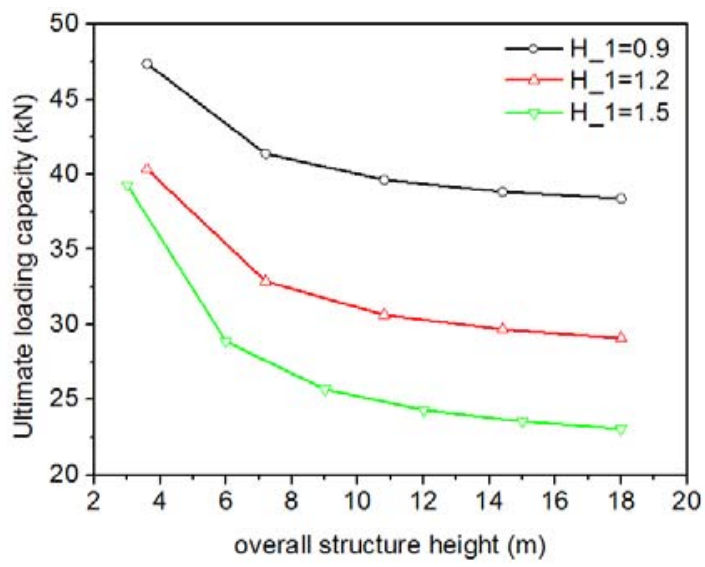

Figure 23. Overall Structure Height Effect on the Bearing Capacity 


\section{DESIGN METHOD}

Based on parameter analyses in Section 4, the main influencing factors om the ultimate bearing capacity of the mortise-tenon steel-tube scaffold are storey height, height of bottom horizontal tube, height of cantilever bar, X-bracing layout, and overall structure height. Among them, storey height is the most important influencing factor. In this section, coefficients $\beta_{1}, \beta_{2}, \beta_{3}$, and $\beta_{4}$ were introduced to consider the effects of the X-bracing layout, height of bottom horizontal tube, height of cantilever bar, and overall structure height on the ultimate bearing capacity respectuvely. The ultimate bearing capacity of the mortise-tenon steel-tube scaffold was calculated from

$P_{c r}=\frac{\beta_{1} \beta_{2} \beta_{3} \beta_{4} N_{f}}{\gamma_{s}}$,

where $N_{f}$ is the standard value of the ultimate bearing capacity of the mortise-tenon steel-tube scaffold without X-bracing. This value is only related to storey height and can be determined according to Table $4 ; \beta_{1}$ is the influence coefficient of X-bracing, which is only related to storey height and can be determined according to Table $5 ; \beta_{2}$ is the influence coefficient of the height of the bottom horizontal tube, which is only related to the height of the bottom horizontal tube and can be determined according to Table 6; $\beta_{3}$ is the influence coefficient of the height of the cantilever bar, which is only related to the height of the cantilever bar and can be determined according to Table 7; $\beta_{4}$ is the influence coefficient of overall structure height, which is related to the overall structure height and storey height and can be determined according to Table $7 ; \gamma_{s}$ is the safety factor and is determined as 1.5 according to engineering experiences [22].

To verify the calculation accuracy of the proposed prediction formula (1), 11 structural models of the mortise-tenon steel-tube scaffold were designed randomly. The ultimate bearing capacities were determined by both FE numerical analysis method presented in Section 4 and the proposed prediction formula (1). Comparison results are listed in Table 8. The maximum error between the calculated results and the FE numerical simulation results was $6.08 \%$, which could meet engineering application requirements.

Table 4. Basic Bearing Ability of Mortise-tenon Steel-tube Scaffold

\begin{tabular}{|c|c|c|c|c|c|}
\hline Storey height $(\mathrm{m})$ & 0.6 & 0.9 & 1.2 & 1.5 & 1.8 \\
\hline $\begin{array}{l}\text { Bearing capacity of single member } \\
(\mathrm{kN})\end{array}$ & 52.30 & 40.02 & 31.94 & 26.20 & 22.66 \\
\hline \multicolumn{6}{|c|}{ Table 5. Increase Coefficient of X-bracing } \\
\hline Storey height (m) & 0.6 & 0.9 & 1.2 & 1.5 & 1.8 \\
\hline $\begin{array}{l}\text { Increase coefficient of bearing } \\
\text { capacity }\end{array}$ & 1.01 & 1.24 & 1.45 & 1.49 & 1.30 \\
\hline
\end{tabular}


Table 6. Adjustment Coefficients of Height of Bottom Horizontal Tube and Height of Cantilever Bar

\begin{tabular}{lccccc}
\hline Height (m) & 0.1 & 0.2 & 0.3 & 0.4 & 0.5 \\
\hline $\begin{array}{l}\text { Adjustment coefficients of height of } \\
\text { cantilever bar }\end{array}$ & 1.00 & 1.00 & 1.00 & 0.91 & 0.81 \\
$\begin{array}{l}\text { Adjustment coefficients of height of } \\
\text { bottom horizontal tube }\end{array}$ & 1.00 & 1.00 & 1.00 & 1.00 & 0.93 \\
\hline
\end{tabular}

Table 7. Adjustment Coefficients of Overall Structure Height

\begin{tabular}{cccccc}
\hline \multirow{2}{*}{$\begin{array}{c}\text { Storey height } \\
(\mathrm{m})\end{array}$} & 4 & 8 & 12 & 16 & 20 \\
\cline { 2 - 6 } & 1.07 & 1.00 & 0.96 & 0.93 & 1.07 \\
0.6 & 1.15 & 1.00 & 0.96 & 0.94 & 0.93 \\
0.9 & 1.22 & 1.00 & 0.93 & 0.90 & 0.88 \\
1.2 & 1.35 & 1.00 & 0.94 & 0.85 & 0.84 \\
1.5 & 1.50 & 1.00 & 0.72 & 0.64 & 0.60 \\
1.8 & & & &
\end{tabular}

Table 8. Comparison between Simplified Calculation Results and Numerical Simulation Results

\begin{tabular}{ccccccccc}
\hline $\mathrm{H}$ & $\mathrm{H} \_1$ & $\mathrm{~S} \_1$ & $\mathrm{H} \_2$ & $\mathrm{H} \_3$ & X-bracing & P $_{\text {cr-FEM }}$ & P $_{\text {cr-S }}$ & Error \\
\hline 16.0 & 0.9 & 0.9 & 0.3 & 0.4 & $\mathrm{~N}$ & 38.84 & 37.79 & -2.70 \\
7.95 & 0.9 & 0.9 & 0.3 & 0.4 & $\mathrm{~N}$ & 41.34 & 40.02 & -3.19 \\
7.95 & 0.9 & 0.9 & 0.3 & 0.5 & $\mathrm{~N}$ & 39.87 & 40.02 & 0.38 \\
7.95 & 0.9 & 0.9 & 0.5 & 0.4 & $\mathrm{~N}$ & 40.29 & 40.02 & -0.67 \\
7.95 & 1.2 & 0.9 & 0.3 & 0.4 & $\mathrm{~N}$ & 32.86 & 31.94 & -2.80 \\
7.95 & 1.8 & 0.9 & 0.3 & 0.4 & $\mathrm{~N}$ & 23.29 & 22.66 & -2.71 \\
7.95 & 0.9 & 0.9 & 0.3 & 0.4 & $\mathrm{Y}$ & 51.07 & 49.62 & -2.84 \\
7.95 & 0.9 & 0.9 & 0.3 & 0.5 & $\mathrm{Y}$ & 46.78 & 49.62 & 6.07 \\
7.95 & 0.9 & 0.9 & 0.5 & 0.4 & $\mathrm{Y}$ & 51.89 & 49.62 & -4.37 \\
7.95 & 1.2 & 0.9 & 0.3 & 0.4 & $\mathrm{Y}$ & 47.80 & 46.31 & -3.12 \\
7.95 & 1.8 & 0.9 & 0.3 & 0.4 & $\mathrm{Y}$ & 29.93 & 29.46 & -1.57 \\
\hline
\end{tabular}

\section{CONCLUSIONS}

The structural performance of the mortise-tenon steel-tube scaffold, a new scaffold system, was studied through finite element numerical simulation. A simplified calculation formula of the ultimate bearing capacity is also presented in this paper. Based on this study, the following conclusions are obtained:

1) A numerical analysis model for the mortise-tenon steel-tube scaffold is presented based on the finite element method and semi-rigid frame theory, which was verified by 11 prototype test data.

2) Under the same structural parameters, the ultimate bearing capacity of the mortise-tenon steel-tube scaffold without X-bracing is approximately $235.59 \%$ higher than that of the coupler-type scaffold. Therefore, the mortise-tenon steel-tube scaffold has significantly better structural performance than the coupler-type scaffold.

3) The X-bracing layout, storey height, and overall structure height influence the ultimate bearing capacity of the mortise-tenon steel-tube scaffold significantly, but the vertical member interval, height of bottom horizontal tube, and height of cantilever bar influence the ultimate bearing capacity slightly. 
4) When the storey heights are $0.6,0.9,1.2,1.5$, and $1.8 \mathrm{~m}$, the ultimate bearing capacities of the scaffold with X-bracing increase by 1.0, 1.24, 1.45, 1.49, and 1.30 times more than those of the scaffold without X-bracing.

5) When the overall structure height is $8,12,16$, and $20 \mathrm{~m}$, the ultimate bearing capacities are approximately $19 \%, 27 \%, 30 \%$, and $29 \%$ lower than the capacities when the overall structure height is $4 \mathrm{~m}$.

6) A calculation formula was presented to calculate the bearing capacity of the mortise-tenon steel-tube scaffold, and the maximum error between calculated results of the simplified calculation formula and the finite element numerical simulation results was $6.08 \%$.

\section{ACKNOWLEDGMENT}

This study was supported by the Tianjin Urban and Rural Construction Commission (Grant No. 2015-4).

\section{REFERENCES}

[1] Chan, S.L., Zhou, Z.H., Chen, W.F., Peng, J.L. and Pan, A.D., "Stability Analysis of Semi-rigid Steel Scaffolding”, Eng Struct 1995, Vol. 17, pp. 568-74. http://www.sciencedirect.com/science/article/pii/014102969500011U

[2] Peng, J.L., Pan, A.D., Rosowsky, D.V., Chen, W.F., Yen, T. and Chan, S.L., "High Clearance Scaffold Systems during Construction-1: Structural Modeling and Modes of Failure”, Eng Struct 1996, Vol. 18, pp. 247-257. http://www.sciencedirect.com/science/article/pii/0141029695001441

[3] Peng, J.L., Pan, A.D., Rosowsky, D.V., Chen, W.F., Yen, T. and Chan, S.L., "High Clearance Scaffold Systems during Construction-2: Structural Analysis and Development of Design Guidelines”, Eng Struct 1996, Vol. 18, pp. 258-267. http://www.sciencedirect.com/science/article/pii/014102969500145X

[4] Peng, J.L., Pan, A.D., Chen, W.F., Yen, T. and Chan, S.L., "Structural Modeling and Analysis of Modular Falsework Systems”, ASCE J Struct Engng 1997, Vol. 123, pp. 1245-51. http://ascelibrary.org/doi/abs/10.1061/(ASCE)0733-9445(1997)123:9(1245)

[5] Peng, J.L., Pan, A.D. and Chan S.L., "Simplified Models for Analysis and Design of Modular Falsework”, J Construct Steel Res, 1998, Vol. 48, pp. 189-209. http://www.sciencedirect.com/science/article/pii/S0143974X98001989

[6] Peng, J.L., Pan, A.D. and Chen, W.F., “Approximate Analysis Method for Modular Tubular Falsework”, ASCE J Struct Engng, 2001, Vol. 127, pp. 256-63. http://ascelibrary.org/doi/abs/10.1061/(ASCE)0733-9445(2001)127:3(256)

[7] Yu, W.K., Chung, K.F. and Chan, S.L., "Structural Instability of Multi-storey Door-type Modular Steel Scaffolds”, Eng Struct, 2004, Vol. 26, pp. 867-61. http://www.sciencedirect.com/science/article/pii/S0141029604000549

[8] Weesner, L.B. and Jones H.L., "Experimental and Analytical Capacity of Frame Scaffolding”, Eng Struct, 2001, Vol. 23, pp. 592-99. http://www.sciencedirect.com/science/article/pii/S0141029600000870

[9] Pienko, M. and Blazik-Borowa, E., "Numerical Analysis of Load-bearing Capacity of Modular Scaffolding Nodes”, Eng Struct, 2013, Vol. 48, pp. 1-9. http://www.sciencedirect.com/science/article/pii/S0141029612004701 
[10] Peng, J.L., Wu, C.W., Chan, S.L. and Huang, C.H., "Experimental and Numerical Studies of Practical System Scaffolds”, J Construct Steel Res, 2013, Vol. 91, pp. 64-75. http://www.sciencedirect.com/science/article/pii/S0143974X13002216

[11] Zhang, H., Rasmussen, K.J.R. and Ellingwood, Bruce R., "Reliability Assessment of Steel Scaffold Shoring Structures for Concrete Formwork”, Eng Struct, 2012, Vol. 36, pp. 81-89. http://www.sciencedirect.com/science/article/pii/S0141029611004731

[12] Zhang, H. and Rasmussen, K.J.R., "System-based Design for Steel Scaffold Structures using Advanced Analysis”, J Construct Steel Res, 2013, Vol. 89, pp. 1-8. http://www.sciencedirect.com/science/article/pii/S0143974X13001557

[13] Zhang, H., Chandrangsu, T. and Rasmussen, K.J.R., "Probabilistic Study of the Strength of Steel Scaffold Systems”, Struct Saf, 2010, Vol. 32, pp. 393-401. http://www.sciencedirect.com/science/article/pii/S0167473010000196

[14] Godley, M.H.R and Beale, R.G., "Sway Stiffness of Scaffold Structures”, The Structural Engineer, 1997, Vol. 75, No. 1, pp. 4-12.

[15] Beale, R.G. and Godley, M.H.R., "Numerical Modeling of Tube and Fitting Access Scaffold Systems”, Advanced Steel Construction, 2006, Vol. 2, pp. 199-223. http://ascjournal.com/

[16] Beale, R.G., "Scaffold Research: A Review”, J Construct Steel Res, 2014, Vol. 98, pp. 188-200.

http://www.sciencedirect.com/science/article/pii/S0143974X14000388

[17] Ao, H.F. and Li, G.Q., "Investigation of Overall Load-bearing Stability Capacity of Tube-and-coupler Scaffolds”, Chinese Quarterly of Mechanics, 2004, Vol. 25, pp. 213-218. (In Chinese)

[18] Yue, F., Yuan, Y., Li, G.Q., Ye, K.M., Chen, Z.M. and Wang, Z.P., "Wind Load on Integral-lift Scaffolds for Tall Building”, ASCE, J Struct Engng, 2005, Vol. 131, pp. 816-24.

http://ascelibrary.org/doi/abs/10.1061/(ASCE)0733-9445(2005)131:5(816)

[19] Liu, H.B., Zhao, Q.H., Wang, X.D., Zhou, T., Wang, D., Liu, J. and Chen, Z.H., "Experimental and Analytical Studies on the Stability of Structural Steel Tube and Coupler Scaffolds without X-bracing”, Eng Struct, 2010, Vol. 32, pp. 1003-1015. http://www.sciencedirect.com/science/article/pii/S0141029609004210

[20] Liu, H.B., Chen, Z.H., Wang, X.D. and Zhou, T., “Theoretical Analysis and Experimental Research on Stability Behavior of Structural Steel Tube and Coupler Falsework with X-bracing”, Advanced Steel Construction, 2010, Vol. 6, No. 4, pp. 946-962. http://ascjournal.com/

[21] He, X.Y., "Study of the Ultimate Bearing Capacity of Full-hall Formwork Support System of Mortise and Tenon Joints”, Tianjin: Tianjin University, 2014. (In Chinese)

[22] Christopher Souder. Temporary Structure Design. Wiley, 2014. 